\title{
Integrated Teaching of Extreme Geometric Problems in Vietnam
}

\author{
Ngoc-Giang Nguyen \\ Doctor of Banking University of Ho Chi Minh City \\ 36 Ton That Dam, Nguyen Thai Binh ward, district 1, \\ Ho Chi Minh City, Vietnam
}

\begin{abstract}
Integrated teaching is a modern, learner-centered trend. Today, Vietnam is strongly innovating from teaching academic knowledge to integrated teaching. Integrated teaching helps learners to develop their competencies. This method makes students to be active and creative. Students have more motivation in learning. Integrated teaching means helps us to find the relationship between these knowledge, methods and other ones. The above things are illustrated by teaching geometric extremes. This is a practical problem in Hau Giang, Vietnam. Teacher gives questions and students answer them. These questions are pedagogic. In addition, the article gives some results of empirical investigation confirming the superiority of integrated teaching compared to traditional teaching. The article proposes a number of research results on the concept of integration and features of integration. Some features of integration are subjective, association, useful combination, expression of introvert and extrovert orientation, creating a unified block, in a certain context.
\end{abstract}

Keywords: Integrated teaching; concept; characteristics; transformations; experiment.

\section{Introduction}

In Vietnam, integrated teaching is receiving a lot of special attention. The general education program considers integrated teaching as a solution to help students develop their abilities. Integrated teaching has the advantages such as helping students synthesize all the knowledge to solve the problem, discovering the relationship between math problems and practical problems and developing thinking, especially creative thinking.

The issue of integrated teaching has been concerned by many authors and organizations. For example, Zhbanova K. S et al (2010) compared the similarities and differences between traditional teaching and integrated teaching. Marshall, J (2005) thought of integrating the fields of art, teaching and creativity. Park, M 
(2008) noticed the integration of the program for elementary school teachers in Korea. Lang, M and Olson, J (2000) studied integrated science teaching. ERIC Development Team (2000) paid attention to the standard program integration. Meanwhile Bailey, L. B (2010) paid attention to the content and pedagogical knowledge in integrated mathematics. Ding, G (2010) introduced a new theory of technology and integrated education. Irwin, C (1992) paid attention to the social aspect of integration. In Vietnam, this topic has also been studied by many people. Nguyen, K. H and Huynh, C. M. H (2013) mentioned integrated teaching in schools. Do, H. T (2016) paid attention to integrated natural science teaching. Nguyen, T. S. (2017) studied integrated teaching for mathematics at high schools. Tran, V. (2014) studied practical issues in teaching. Nguyen, H. C (2006) and Ha, TL H and Dang, T. O (2015) paid attention to the topic of integrated teaching, ... However, there are no specific studies on integrated teaching of flat geometric extremes in Vietnam. Therefore, this article will mention the concept of integration, how to build integrated teaching as well as give some experimental results on the integration of flat geometric extremes.

\section{Research content}

This section refers to the conception of integration and an illustrated example on teaching geometric extremes

\subsection{Conception of integration}

According to the Oxford Advanced Learner's dictionary, the word integrated is defined as follows: "in which many different parts are closely connected and work successfully together".

Vietnamese dictionary writes: "Integration is combining different activities, programs or components into a function block. Integration means unity, harmony, union "(Hoang, P., et al, 1988).

Education Dictionary writes: "Integration in teaching is the act of linking subjects to research, teaching and learning of the same field or several different areas in the same teaching plan (Bui, $\mathrm{H}$., et al, 2001)

Nguyen, T.T.B., Truong, T. P (2019) said: "Integration is a combination, harmony of elements, different parts that have close relationship, interaction and mutual support in the same or more things, phenomena, fields ... into a unified function block to solve a specific problem or situation.

Through the views and definitions of integration, we realize that integration has many different approaches. Although there are many different approaches, integration is never defined without a relationship. It can be said that the relationship is the most important word to explain the integration. Second, it is the environment of integration. Third, it is an object related to the integration. Fourth, it is the connection into a block of integration and ultimately the success, efficiency, meaning of integration. From this analysis, we give the definition of integration as follows:

Integrating an object, the phenomenon of a subject means that the subject connects things, phenomena to related things and phenomena, as well as connecting within the phenomenon itself into a unified, useful block, in a certain context. 


\subsection{Features of integration}

This section refers to the features of integration.

\subsubsection{Integration is subjective}

Depending on the different objects, integration is different. In the same topic, for this person, he integrates that topic in this way, but for another he integrates in another way. Integration depends on the perspective of life, competence and knowledge of the integrated subject. The integrated subject can be an individual or many people. Integration depends on the level of knowledge, civilization and living environment of the subject. (Nguyen, 2019)

\subsubsection{Association}

It can be said that integration is one of the ways that we use most often in science and life. In terms of phenomena it may have many different manifestations but in terms of the nature of integration it is completely the same.

For example, my daughter asked my mother to help her make the doll clothes. My mother was busy and answered her that she couldn't do it. My daughter asked me to take her to her friend's house to ask her to do it. Thus, in her mind, there was an "association" of making doll clothes and people making doll clothes, which is an expression of integration.

The second example that is the acquisition of our own knowledge. The nervous system consists of nerve cells connected together in tubes and networks throughout the body. It has been discovered that the information contained in a cluster of neurons is more easily activated if the cluster of cells has more "connections" to other cells. When we learn a new theorem, concept, nature, rule or method, the nervous system remembers it in a cluster of neurons and thereby creates a bridge from that cell cluster to other cells. In order to create a bridge, it is necessary to recognize the relationship with each other. That is an expression of integration.

The third example, Vygotsky is a famous Russian psychologist. He is the one who thinks that in order to teach children successfully, the teaching needs to foresee the cognitive development of children, by approaching the "nearest development area" of the child. That means, teachers should not raise an activity or task that students cannot do, discourage students or simply students do not want to learn. Students only acquire new knowledge and skills in their "nearest development area". New knowledge, new skills are not too high, not too difficult to be outside of the "reach" of students. It only requires students to make efforts, to try to gain knowledge and skills. In order for students to gain new knowledge, students must have the old knowledge base and the relationship between new knowledge and old knowledge. If this relationship is clear, students will gain new knowledge. If this relationship is fuzzy, then with all efforts the students will be able to acquire new knowledge. If the relationship is not visible, the student will not be able to comprehend new knowledge. The connection between old and recent knowledge is an expression of integration. Our new knowledge acquisition scheme based on the old knowledge base is as follows: 


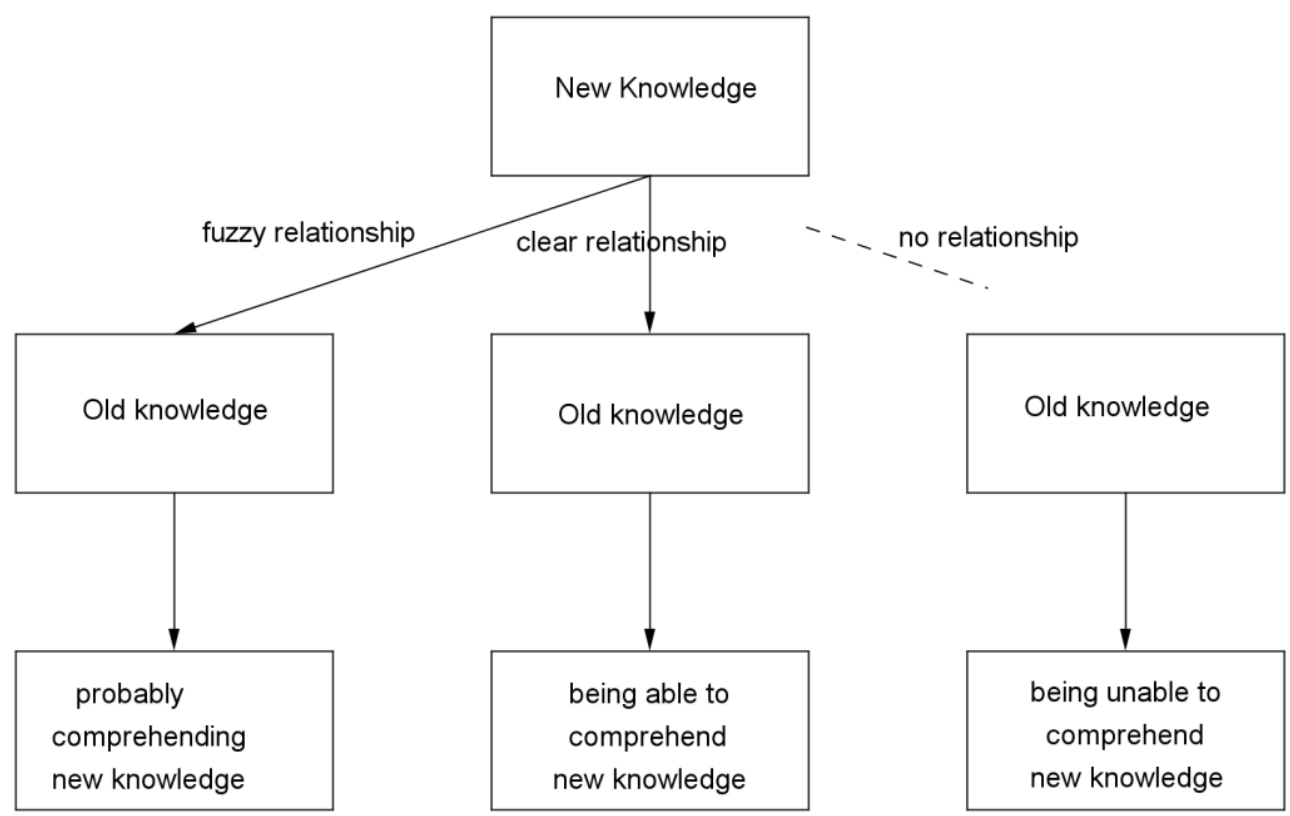

Figure 1: Diagram of the new knowledge form of a person

Thus, the important characteristic of integration is the relationship, the association. We seek relationships, internal associations and relationships, external associations of things and phenomena. The relationship, the connection between this thing and this phenomenon with other things and phenomena is not a heavenly relationship, $100 \%$ new, nothing related to the old, but the relationship must have inherit, have a certain initial foundation. Integrated teaching activities are activities that detect the connection between the old and the new. No matter how good a teacher is, when he teaches integrated learning, the link between his old and new knowledge is out of the student's reach, that integrated teaching activity is regarded as a failure. The diagram shows this as follows:

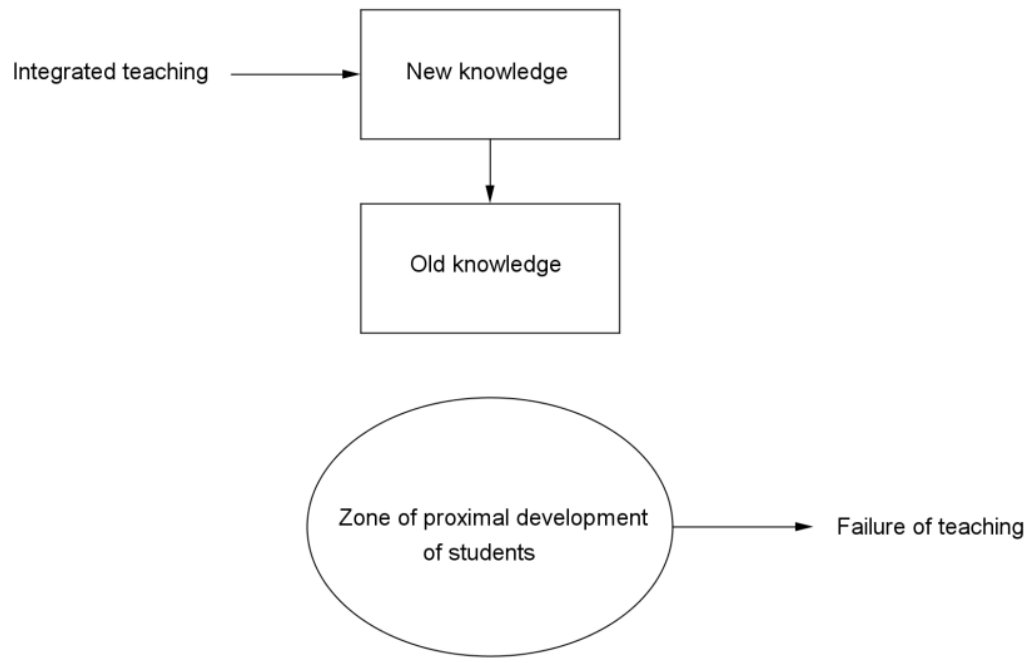

Figure 2: Integrated teaching diagram

(Nguyen, 2019) 


\subsubsection{Useful combination}

The next feature of integration is the usefulness of combining. This useful combination shows us the effectiveness of what we are doing, saving time, effort and money. Second, the combination must give us educational, pedagogical and meaningful results in life. We consider the following illustration problems:

\section{Problem 1}

Calculate the sum: $S=1+2+3+\ldots+99+100$.

If we solve the problem by "accumulating" together as follows:

$$
\begin{aligned}
& 1+2=3 \\
& 3+3=6 \\
& 6+4=10
\end{aligned}
$$

then the combination of the problem and this solution is not useful. Because it will lead us to errors in the calculation and take a lot of time and effort.

\section{Problem 2}

Your hands have 10 fingers, because of playing with a knife, you have lost 2 fingers. How many fingers do you have?

This problem is an anti-educational problem, not pedagogical, so it cannot be considered an integrated problem. We have to eliminate these types of problems. (Nguyen, 2019)

\subsubsection{Expression of introvert and extrovert orientation}

The combination in integration has two characteristics. The first characteristic shows the introvert, which is the inner combination of things and phenomena. For example, different ways to find solutions and approaches of math problems. The second characteristic represents the extrovert, which is a combination of this thing and phenomenon with other things and phenomena. Examples include discovery, expansion, generalization, analogy and specialization activities to find the inverse problem of a given problem. (Nguyen, 2019)

\subsubsection{Creating a unified block}

The next feature of integration is to form a unified block. The results from the combinations we make are not separate, unrelated results. They must form a unified block. This can be illustrated by visualizing the results obtained as "water pipes". If the pipelines are separate from each other, without any link, it will be considered that we do not have "integration". Conversely, if we connect pipes with threads, or welds together, they will form a unified block and help the water flow to the shower, the sink, the hot water bath and the toilet bowl. That is integration. The second example of integration is expressed in making a thesis. If the chapters of a thesis are separate from each other, each chapter is a separate entity, it will not be a thesis. On the contrary, if the chapters of the thesis are closely linked, this chapter is the premise for the implementation of 
the other chapter, the other chapter addresses the remaining problems of this chapter; if the content of those chapters is complementary, with an organic and close relationship, we will get a complete thesis. That is an expression of integration. (Nguyen, 2019)

\subsubsection{In a certain context}

The last characteristic of integration is in a certain context. This context can be the culture, scientific fields or life of things and phenomena. The context can be space, time, etc. For example, we integrate Math with life and have the following problem:

\section{Problem 3}

Nam's food tray has 5 pieces of pork. Hung's food tray has 4 pieces of pork. How many pork pieces are available in both Nam and Hung's food trays?

Obviously this problem is only a pure addition, the solution is not difficult. But if we take the context of Muslim countries, this is an unacceptable problem. Muslim countries abstain from eating pork. Therefore, teaching and learning integrated problems must be consistent with the culture, the fine traditions of the integrated problem that are taught.

\section{Problem 4}

Calculate the sum: $S=1+2+3+\ldots+99+100$.

The combination of "cumulative" thinking together and the problem as mentioned above is not integration. However, this is only a field of Mathematics. In the field of Informatics, in particular in the field of programming, this combination is integration. Because computers can perform "boring" jobs with high accuracy, almost no errors. A combination of mathematical thinking and the problem often illustrated for the "left side" of Mathematics, then in the field of Informatics is an indispensable combination. It can be said that if one does not learn how to "accumulate" together, the person never understands the "human machine" thinking.

Thus, if the context is the time before the Information Technology era and after having Information Technology, the perspective of integration is different. Different context, the integration is also different. This problem in this country is an integrated problem but also that problem for other countries is a problem that is banned because it is meaningless, contrary to moral standards, social rules.

(Nguyen, 2019)

\subsection{An example to illustrate teaching through geometric extremes}

\section{Example 1}

On the occasion of the 10th anniversary of the establishment of Hau Giang province, Vietnam, people want to make a road from point A to point B on the banks of a river, the figures are shown on the drawing, the road is made following the kinked AMNB (point A connects with point $\mathrm{M}$, point $\mathrm{M}$ connects with point $\mathrm{N}$, point $\mathrm{N}$ connects with point $\mathrm{B}$ ). Knowing that the cost of constructing $1 \mathrm{~km}$ of the road containing point $\mathrm{B}$ is 1.3 times more than the cost 
of building $1 \mathrm{~km}$ of the road on the shore containing point $\mathrm{A}$, the cost of making $\mathrm{MN}$ bridge at any location is the same. How far from $\mathrm{H}$ must a bridge be built at point $\mathrm{M}$ to make the minimum cost of road construction?

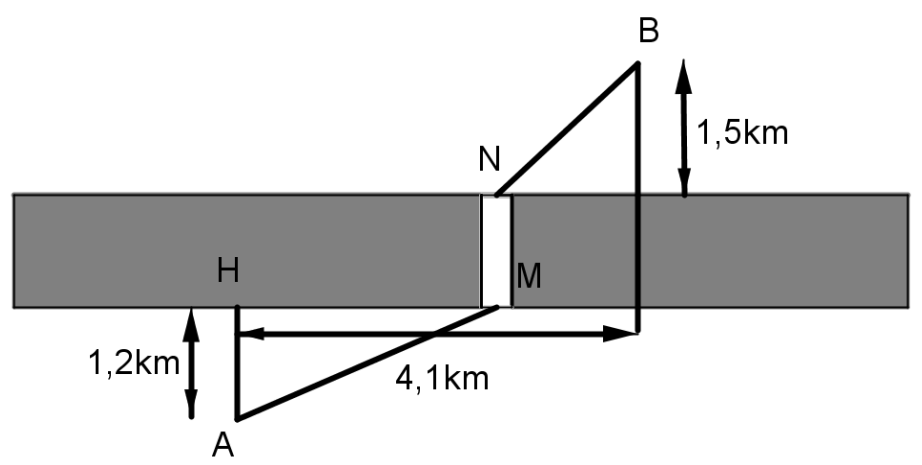

Figure 3: Building a bridge across the river in Hau Giang

(The provincial excellent student exam for solving math problems on calculators in 2013-2014, Hau Giang province, Vietnam)

In this article, we will explore the integration of Mathematics, Computer Science and Physics through this practical example.

Teacher: Can you tell the general problem of this problem?

\section{Student:}

\section{Example 2}

The two villages are located at two locations A and B, separated by one river (assuming that the two banks of the river are two parallel lines) (figure). It is intended to build a MN bridge across the river (of course the bridge must be perpendicular to the river bank) and make two straight lines from $\mathrm{A}$ to $\mathrm{M}$ and from $\mathrm{B}$ to $\mathrm{N}$. Determine the location of the $\mathrm{MN}$ bridge so that $A M+M N+N B$ is the shortest. (Nguyen, 2001), (Nguyen, 2017).

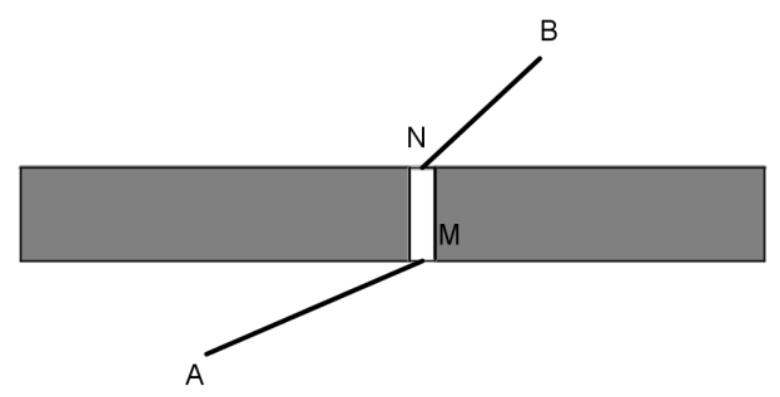

Figure 4: Building a bridge between two villages

Teacher: From Example 2, the author has changed it into a more difficult problem when adding that the cost of building $1 \mathrm{~km}$ of the road on the shore containing point $\mathrm{B}$ is 1.3 times higher than the cost of building $1 \mathrm{~km}$ of the road on the shore containing point $\mathrm{A}$. 
Now, we will solve the problem of example 1 with 3 steps.

Step 1 (Let's abstract the example 1)

Set: $x=H M(0 \leq x \leq 4,1) \Rightarrow A M=\sqrt{x^{2}+1,44} ; B N=\sqrt{(4,1-x)^{2}+2,25}$.

Suppose that $a$ is the amount of money to make $1 \mathrm{~km}$ of the road on the shore with point $\mathrm{A}$, then the cost to make two $\mathrm{AM}$ and $\mathrm{BN}$ sections is: $f(x)=a \sqrt{x^{2}+1,44}+1,3 a \sqrt{(4,1-x)^{2}+2,25}$.

Teacher: We need to find the answer to the following math problem:

\section{Example 3}

Find the smallest value of the function with $a$ given positive value:

$$
f(x)=a \sqrt{x^{2}+1,44}+1,3 a \sqrt{(4,1-x)^{2}+2,25} .
$$

Step 2 (Solving the problem)

$$
f^{\prime}(x)=\frac{a x}{\sqrt{x^{2}+1,44}}-\frac{1,3 a(4,1-x)}{\sqrt{(4,1-x)^{2}+2,25}} .
$$

Solve the equation $f^{\prime}(x)=0$, we get $x_{0}=x \approx 2,6304$.

We can calculate $f\left(x_{0}\right) \approx 5,6211 a ; f(0) \approx 6,8755 a ; f(4,1) \approx 6,2220 a$.

Therefore $\min _{[0 ; 4,1]} f(x)=f\left(x_{0}\right)$. So $H M \approx 2,6304 \mathrm{~km}$.

Step 3 (Inferring the practical problem)

According to the above results, we have to build a bridge at point $\mathrm{M}$ which is $2,6304 \mathrm{~km}$ from point $\mathrm{H}$ so that the cost of road construction is the smallest.

Teacher: Through the above analysis, we see that example 1 is the same problem as example 2. The careful study of example 2 will clarify example 1 and these two examples have an organic attachment together.

Teacher: Let's find the sum of $A M+M N+N B$ with the smallest value on GeoGebra software and propose the corresponding solution for example 2 to express the integration of Math and Informatics.

Teacher: Predict the position of $\mathrm{MN}$ so that $A M+M N+N B$ has the smallest value on GeoGebra software as follows:

\section{Step 1. Drawing the shape.}

- Draw two rivers $d, d^{\prime}$.

- Draw two points $A, B$ on both sides of the river.

- Draw two points $N, M$ on the two banks of the $d, d^{\prime}$ respectively so that $N M$ is perpendicular to the two banks of the river.

- Connecting the $A M, M N, N B$. 
- Measure the lengths of straight segments $A M, N B$.

- Measure the total length of straight segments $A M+N B$.

- Draw the perpendicular axis system $O x y$ so that $O y$ passes through point $A$ and $O x$ belongs to straight line $d$.

- Draw on $O y$ a point $\mathrm{F}$ so that $O F$ equals the total length of straight segments $A M+N B$.

- The intersection point of the line which is perpendicular to Oy at $\mathrm{F}$ and the line which is perpendicular to $\mathrm{Ox}$ at $\mathrm{N}$ is called $\mathrm{E}$ (the degree of point $\mathrm{E}$ represents the total measurement of the length of straight segments $A M+N B$ )

\section{Step 2. Create a trace}

- Create a trace for $\mathrm{E}$, move $\mathrm{N}$, we get the trace of point $\mathrm{E}$.

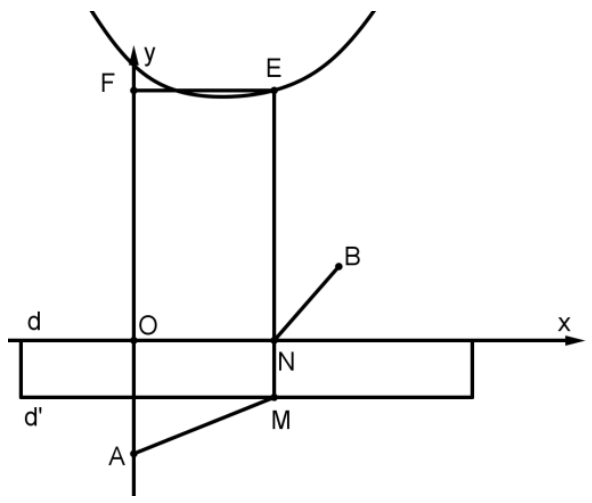

Figure 5: The trace of point $\mathrm{E}$

Move point $\mathrm{N}$ on $\mathrm{d}$ so that the degree of point $\mathrm{E}$ reaches the smallest value. Now watching, we see $A M / / B N$.

Solution 1 (Mathematical Solution)

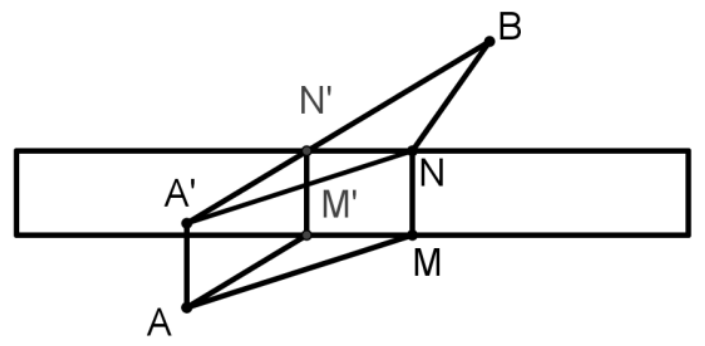

Figure 6: Find the location of MN

Suppose that, if the river is very narrow, so narrow that the river banks $d$ and $d$ 'overlap. Move point $M$, we find the position of $M$ which is the intersection of the river bank $\mathrm{d}$ and section $\mathrm{AB}$ (we know this is the familiar problem: $M A+M B \geq A B \Rightarrow M A+M B$ is the shortest when $\mathrm{M}$ is the intersection of $\mathrm{d}$ and straight line $A B)$. Thereby leading to using the translation $T_{\overline{M N}}$ which 
allows "to go ahead" through the bridge and transfer to the above problem. Set $\vec{v}=\overrightarrow{M N}$ (The vector $\vec{v}$ is perpendicular to the river bank and the length is equal to the width of the river). We have $T_{\vec{v}}: \begin{aligned} & A \mapsto A^{\prime} \\ & M \mapsto N\end{aligned}$

So $A M=A^{\prime} N$. Therefore $(A M+M N+N B)$ is the shortest. $\Leftrightarrow\left(A^{\prime} N+N B\right)$ is the shortest. $\Leftrightarrow A^{\prime}, N, B$ are in line.

\section{How to draw $M, N$ :}

- Draw $A^{\prime}$ so that $\overrightarrow{A A^{\prime}}=\vec{v}$.

- Draw $N$ which is the intersection of $A^{\prime} B$ and $d$.

- Draw $M$ so that $\overrightarrow{N M}=-\vec{v}$.

- $M, N$ are positions to be searched.

Teacher: The following is an integration of Math and Physics.

\section{Solution 2 (Physics Solution)}

This problem we can solve by using pure geometry. However, we can also use the mechanics method to solve. We will solve example 2 by stating the more general problem as follows:

\section{Example 4}

On different river banks there are 5 residential areas $A_{1}, A_{2}, A_{3}, B_{1}, B_{2}$ ( $A_{1}, A_{2}, A_{3}$ on a river bank, $B_{1}, B_{2}$ is on the other side (figure)). We need to build a $C D$ bridge so that the total length of the lines $A_{1} C, A_{2} C, A_{3} C ; B_{1} D, B_{2} D$ from residential areas to the bridge is minimal (the river banks are parallel, the bridge is perpendicular to the river bank)?

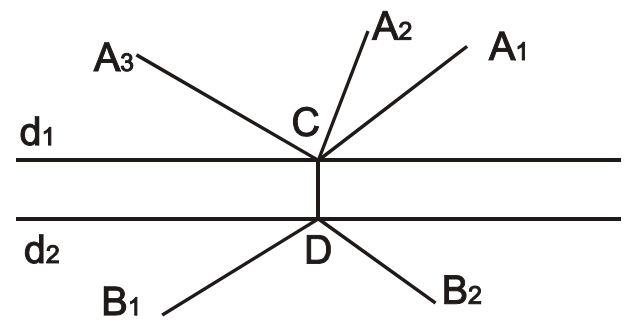

Figure 7: Five residential areas

To solve this problem, consider the following mechanical system. A rigid CD can slide non-friction on rails and is always perpendicular to rails. We consider the five pulleys rotating around an axis (nail) on a vertical wall at points $A_{1}, A_{2}, A_{3}$ and $B_{1}, B_{2}$ (figure). 


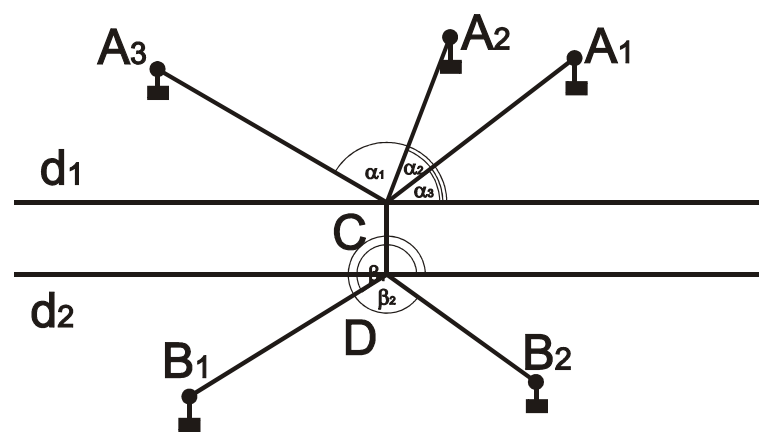

Figure 8: Physical image of the problem of five residential areas on either side of the river

The five threads $D C A_{1}, D C A_{2}, D C A_{3}, C D B_{1}, C D B_{2}$ are threaded through five pulleys respectively in $A_{1}, A_{2}, A_{3}$ and $B_{1}, B_{2}$. Five threads are connected at one end to the C or D of the bar and at the other end of each thread we hang the same heavy masses. .

Consider the forces acting on the $\mathrm{CD}$. On the $\mathrm{C}$ end of the bar, the tension forces of the threads $A_{1} C, A_{2} C, A_{3} C$ are $\overrightarrow{T_{1}}, \overrightarrow{T_{2}}$ and $\overrightarrow{T_{3}}\left(\left|\overrightarrow{T_{1}}\right|=\left|\overrightarrow{T_{2}}\right|=\left|\overrightarrow{T_{3}}\right|\right.$ due to the same heavy masses) and the $\overrightarrow{N_{1}}$ reaction from the first rail side.

At the $\mathrm{D}$ end of the bar, the tension forces of the threads $B_{1} D, B_{2} D$ are $\vec{T}_{4}$ and $\overrightarrow{T_{5}}\left(\left|\overrightarrow{T_{1}}\right|=\left|\overrightarrow{T_{2}}\right|=\left|\overrightarrow{T_{3}}\right|=\left|\overrightarrow{T_{4}}\right|=\left|\overrightarrow{T_{5}}\right|\right)$ and the reaction $\overrightarrow{N_{2}}$ from the second rail side (in the figure $N_{1}$ and $N_{2}$ forces are perpendicular to the rails, and the $\vec{T}_{i}(i=\overline{1,5})$ forces are equal.

Since $\overrightarrow{T_{1}}+\overrightarrow{T_{2}}+\overrightarrow{T_{3}}+\overrightarrow{T_{4}}+\overrightarrow{T_{5}}+\overrightarrow{N_{1}}+\overrightarrow{N_{2}}=\overrightarrow{0}$ and $\overrightarrow{N_{1}}, \overrightarrow{N_{2}} \perp d_{1}, d_{2}$, we bring the projection onto the straight line d parallel or coincide with $d_{1}$ or $d_{2}$, we get

$\left|\overrightarrow{T_{1}}\right| \cos \alpha_{1}+\left|\overrightarrow{T_{2}}\right| \cos \alpha_{2}+\left|\overrightarrow{T_{3}}\right| \cos \alpha_{3}+\left|\overrightarrow{T_{4}}\right| \cos \beta_{1}+\left|\overrightarrow{T_{5}}\right| \cos \beta_{2}=0$

Or Hay $\cos \alpha_{1}+\cos \alpha_{2}+\cos \alpha_{3}+\cos \beta_{1}+\cos \beta_{2}=0\left(^{*}\right)$

(angles are calculated in a counter-clockwise direction, $0 \leq \alpha_{1} \leq \pi, \pi \leq \beta_{j} \leq 2 \pi, i=1,2,3, j=1,2$; see the figure)

\section{Comment}

1. Although the equation $\left(^{*}\right)$ does not give us a way to draw $C D$ with a compass and a ruler, it is often useful for solving similar real problems.

2. Example 4 is a problem that no pure mathematical solution has been found so far. Through this, we can see clearly the advantages of applied Physics method in solving some Math problems.

3 . In example 4 , if there is only one residential area on each side of the river, we will get example 2. The equation $\left(^{*}\right)$ gives us $\cos \alpha+\cos \beta=0$, thereby 
deducing $\beta=\pi+\alpha$ (figure), i.e, the $\mathrm{AC}$ and $\mathrm{BD}$ segments must be parallel. In this case, the CD can be drawn with a compass and a ruler. This is the content of example 2 above.

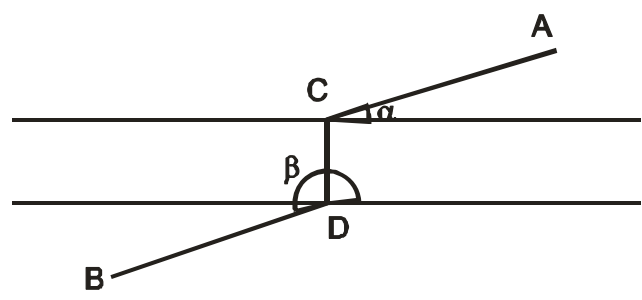

Figure 9: Specialization

Teacher: Integrating Math and Physics by expanding example 2 to a more general problem as follows:

\section{Example 5}

An athlete needs to run from point A to point B. Between those points there is a river whose two banks are parallel lines $\mathrm{x}$ and $\mathrm{y}$ (figure). On the land the athlete runs at velocity $u_{1}$, under the water he swims at velocity $u_{2}$. Suppose that the water in the river is standing still. Prove that the movement time of the athlete from $\mathrm{A}$ to $\mathrm{B}$ will be the smallest, if the angles $\alpha_{1}, \alpha_{2}$ and $\beta$ satisfy the conditions $\alpha_{1}=\alpha_{2}=\alpha$ and $\frac{\sin \alpha}{\sin \beta}=\frac{u_{1}}{u_{2}}$.

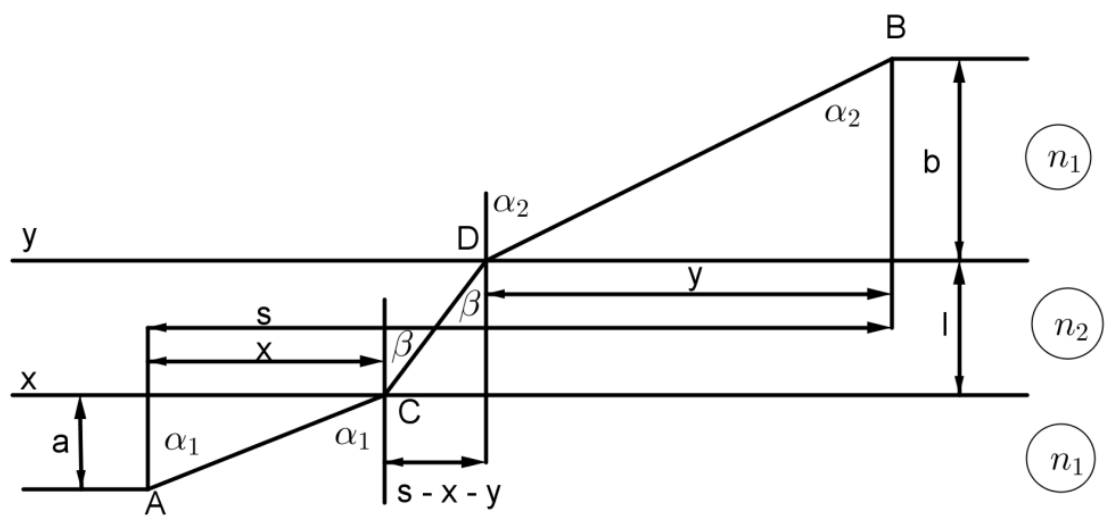

Figure 10: An athlete runs from $A$ to $B$

The solution of the problem by Physics method is as follows:

The movement of the person following the kinking line $A C D B$ can be viewed as the light in the "environment - earth road" transmitted from point A, through the parallel face $x y$ (this river acts as a parallel face $x y$ ) and then emit "environment - earth road ", to point B. The speed of light transmission in "environment - earth road" is $u_{1}$, in the parallel face $u_{2}$. 
Therefore, the refractive index of " environment - earth road ": $n_{1}=\frac{c}{u_{1}}$ and the refractive index of the parallel face $x y: n_{2}=\frac{c}{u_{2}}$ with $c$ is the speed of light in vacuum.

Applying the law of light refraction, we have, at point C: $n_{1} \sin \alpha_{1}=n_{2} \sin \beta$. At point $\mathrm{D}: n_{2} \sin \beta=n_{1} \sin \alpha_{2}$. From $n_{1}=\frac{c}{u_{1}}, n_{2}=\frac{c}{u_{2}}, n_{1} \sin \alpha_{1}=n_{2} \sin \beta$, $n_{2} \sin \beta=n_{1} \sin \alpha_{2}$, we deduce $\alpha_{1}=\alpha_{2}=\alpha$ and $\frac{\sin \alpha}{\sin \beta}=\frac{u_{1}}{u_{2}}$ (Q. E. D).

Teacher: Continue to expand example 2 into another example:

\section{Example 6}

There are two locations A and B on either side of a river with the width of $d$ and water flowing at velocity $V$. One person runs at speed $v$, swimming in quiet water at velocity $u$, he must follow which way from point $\mathrm{A}$ to soak in the water for the shortest time and to go to point $B$ the fastest?

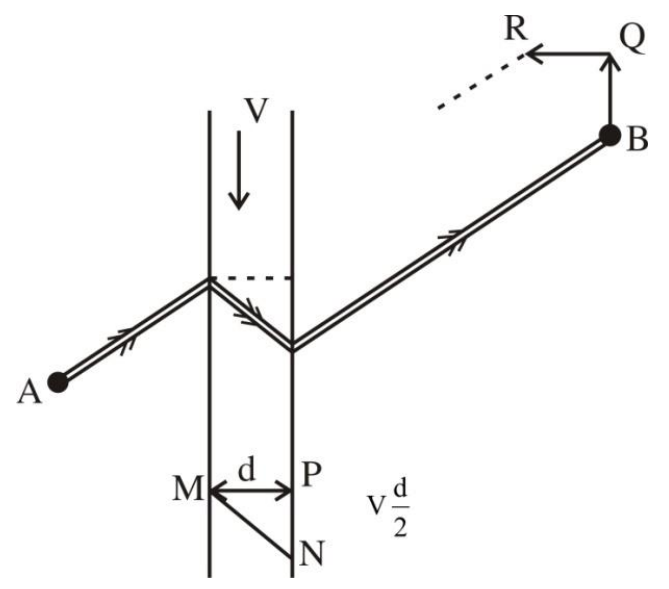

Figure 11: Two locations A and B

Teacher: We solve the problem as follows

In order to soak in the water for the shortest time, the person must swim so that the velocity $u$ is perpendicular to the water flow. So if he swims from $M$, then he will go across the river at $N$ (figure) because of being swept away by a distance equal to $\left(\frac{V}{u}\right) \cdot d$.

So we can determine the fastest path:

From $B$, draw $\overrightarrow{B Q}=-\overrightarrow{P N}\left(B Q=\left(\frac{V}{u}\right) \cdot d\right.$, draw $\overrightarrow{Q R}=-\overrightarrow{M P} \quad(Q R=d)$, connect $\mathrm{AR}$ and we have the fastest path drawn in bold on the drawing. In fact, because 
it is easy to prove this way, the road that that person has to run on land is the same length as the AR distance, and if he follows any other path while ensuring the condition of immersion in the water for the shortest time, the road section to run on land will be larger than AR.

Now, we will consider a point as the case of the circular degradation when the circle has radius $R=0$, we obtain the general problem of example 2 as follows:

Teacher: Integrate Math by expanding a point into a circle.

\section{Example 7}

Two circular cylindrical gasoline storages have bottoms $\left(O_{1} ; R\right)$ and $\left(O_{2} ; r\right)$ respectively and are in two positions separated by one river (assuming that the two banks are two parallel lines) (figure 12). It is intended to build a MN bridge across the river (of course the bridge must be perpendicular to the river bank) and make two straight lines connecting one point $\mathrm{A}$ on $\mathrm{O}$ to $\mathrm{M}$ and from $\mathrm{N}$ to $\mathrm{B}$ on $\mathrm{O}$. Please identify the position of $\mathrm{MN}$ bridge so that $\mathrm{AM}+\mathrm{MN}+\mathrm{NB}$ is the shortest?

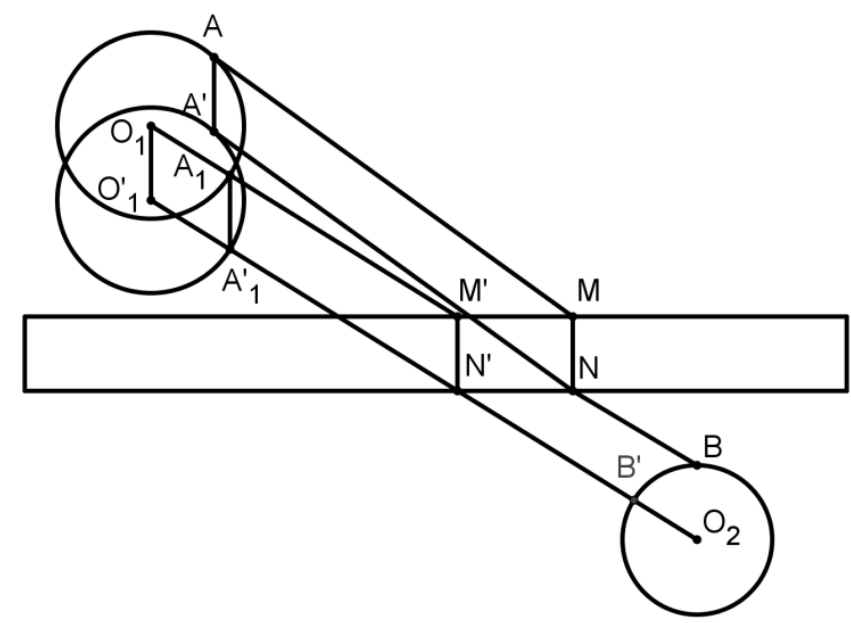

Figure 12: Construction of two gasoline storages

Teacher: In this problem, we do the same as example 2. Can you prove it?

\section{Students :}

Considering the translation of $T_{\overline{M N}}:\left(O_{1}\right) \rightarrow\left(O_{1}^{\prime}\right)$. We have: $A \in\left(O_{1}\right) \mapsto A^{\prime} \in\left(O_{1}^{\prime}\right)$.

The intersections of $O_{1}^{\prime} O_{2}$ with $\left(O_{1}^{\prime}\right)$ and $\left(O_{2}\right)$ are called $A_{1}^{\prime}$ and $B^{\prime}$ respectively; $T_{\overline{N M}}: A_{1}^{\prime} \mapsto A_{1} ; A_{1}^{\prime} B^{\prime}$ cuts the river bank at $\mathrm{N}$, draw point $\mathrm{M}$ so that $\overrightarrow{N^{\prime} M^{\prime}}=\overrightarrow{N M}$ (figure 12). 
For any point $A, M, N, B$ we have:

$$
\begin{aligned}
A M+M N+N B & =A^{\prime} N+M N+N B \geq A_{1}^{\prime} B^{\prime}+M N \\
& =A_{1}^{\prime} N^{\prime}+N^{\prime} B^{\prime}+M^{\prime} N^{\prime}=A_{1} M^{\prime}+M^{\prime} N^{\prime}+N^{\prime} B^{\prime} .
\end{aligned}
$$

So $A_{1}, M^{\prime}, N^{\prime}, B^{\prime}$ are the points to be searched.

Teacher: The problem that is similar and more difficult than problem 7 (also the general problem of example 1) is the following problem:

\section{Example 8}

The two circular cylindrical petrol storages have the bottoms $\left(O_{1} ; R\right)$ and $\left(\mathrm{O}_{2} ; r\right)$ respectively and are in two positions separated by one river (assuming that the two banks of $d, d^{\prime}$ are two parallel lines separated by distance $h$ ). It is intended to build a MN bridge across the river (of course the bridge must be perpendicular to the river bank) and make two straight lines connecting one point $A$ on $\left(O_{1}\right)$ to $M$ and from $N$ to $B$ on $\left(O_{2}\right)$. Suppose that the construction cost on the shore containing point $B$ is $n\left(n \in \mathbb{R}^{*}\right)$ times more than the construction cost of $1 \mathrm{~m}$ of the road on the shore containing point $\mathrm{A}$, the cost of making $\mathrm{MN}$ bridge at any location is the same. How far away from point $\mathrm{H}$ must a bridge be built at point $\mathrm{M}$ and where are positions $\mathrm{A}$ and $\mathrm{B}$ so that the cost of making $A M+M N+N B$ is the smallest? Given that $a, b, c, R, r, h$ all have units of measurement as meters as shown.

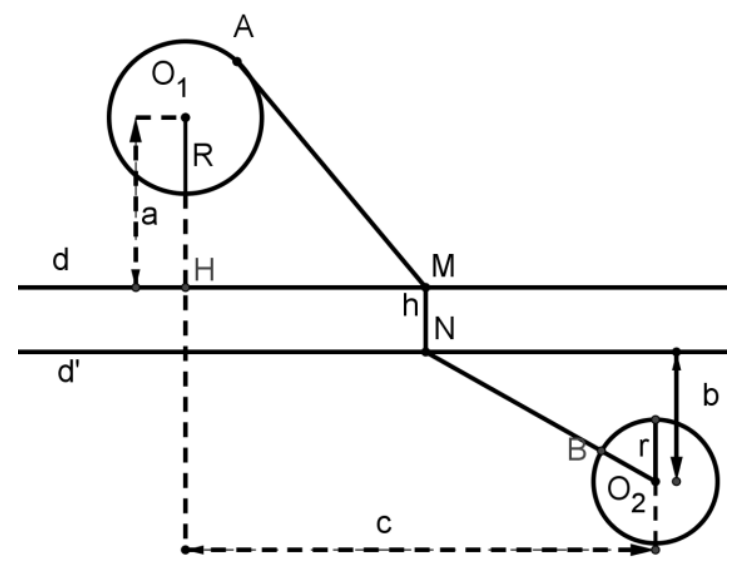

Figure 13: Construction of two gasoline stores taking the cost into account

Teacher: Can you solve it ?

Students: We solve the problem as follows:

Consider the translational method $T_{\overline{M N}}:\left(O_{1}\right) \rightarrow\left(O_{1}^{\prime}\right)$. Now $A \mapsto A^{\prime}$.

We deduce $A M=A^{\prime} N$. 
Because $O^{\prime}{ }_{1} A^{\prime}+A^{\prime} N \geq O_{1}^{\prime} N=O^{\prime}{ }_{1} A^{\prime}{ }_{1}+A^{\prime}{ }_{1} N$. Therefore if extreme happens, $\mathrm{O}_{1}^{\prime}, A_{1}^{\prime}, N$ are aligned.

Similarly, if extreme happens, $N, B, O_{2}$ are also aligned.

Our problem is similar to the problem that finds $N$ on $d^{\prime}$ so that $N O_{1}^{\prime}+n N O_{2}$ reaches the minimum value.

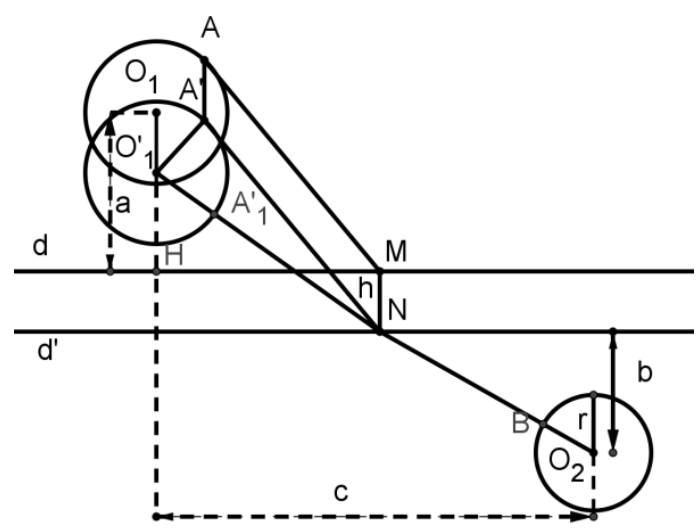

Figure 14: Solution to the problem of constructing two gasoline storages taking the cost into account

Teacher: Consider $M N$ as a degenerate case of the $M P N Q$ rectangle. Expand example 2 to the following general example. Can you expand it?

Students: We do not know.

Teacher: We can expand it as follow:

\section{Example 9}

The two villages are located at two places A and B, separated by one river (assuming that the two banks of the river are two parallel lines) (figure). It is intended to build a rectangular bridge $M P N Q$ across the river (of course, $M Q, P N$ must be perpendicular to the river bank) and make two straight road segments from A to $\mathrm{M}$ and from $\mathrm{B}$ to $\mathrm{N}$. Please locate $M P N Q$ bridge so that the $A M+N B$ is the shortest.

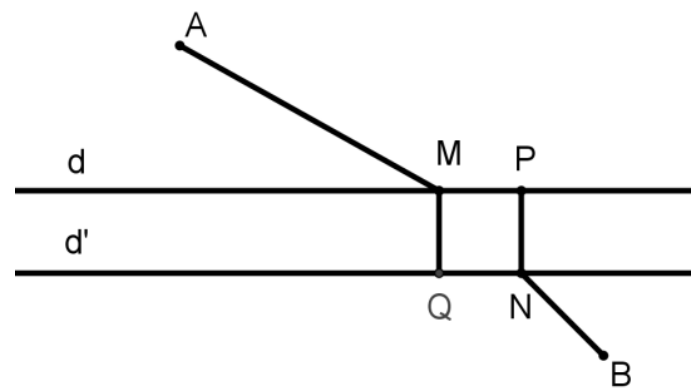

Figure 15: Find the position of $M$ and the position of $N$ 
Predict the position of $M N$ so that $A M+N B$ reaches the smallest value on GeoGebra software:

\section{Step 1. Draw the picture}

- Draw two river banks $d, d^{\prime}$.

- Draw two points $A, B$ on both sides of the river.

- Draw the $M P N Q$ rectangle so that $M, P$ and $N, Q$ are on the banks of $d, d^{\prime}$ respectively so that $M Q, P N$ are perpendicular to the two river banks ( $M P$ has a constant length and $P N$ is equal to the width of the riverbed). ).

- Connecting AM, NB.

- Measure the length of straight segments $A M, N B$.

- Measure the total length of straight segments $A M+N B$.

- Draw the perpendicular axis system $O x y$ so that $O y$ passes through point A and $O x$ belongs to straight line $d$.

- Draw a point $\mathrm{F}$ on $\mathrm{Oy}$ so that $\mathrm{OF}$ equals the total length of straight segments $A M+N B$.

- The intersection of the line perpendicular to $O y$ at $F$ and the line perpendicular to $O x$ at $M$ is called $E$ (the degree of point $E$ represents the total measurement of the length of straight segments $A M+N B$ )

\section{Step 2. Create a trace}

- Create a trace for $\mathrm{E}$, motion $\mathrm{M}$ we obtain a trace of point $\mathrm{E}$.

- We move point $\mathrm{M}$ on $d$ so that the degree of point $\mathrm{E}$ reaches the smallest value. From here we draw the Mathematical solution of the problem.

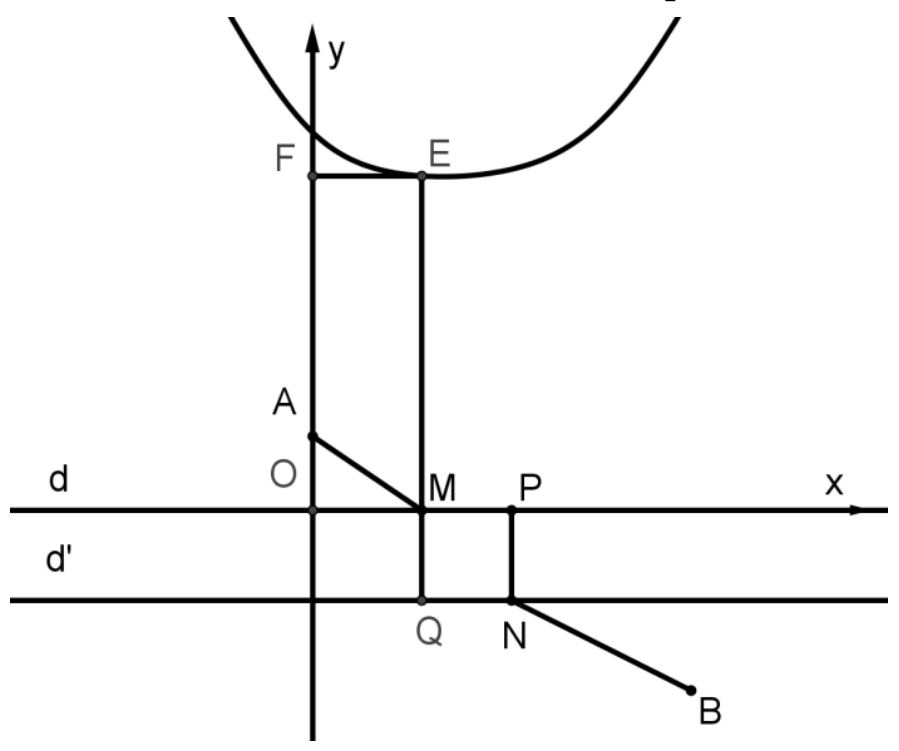

Figure 16: The trace of point $E$ 
Mathematical solution is as follows:

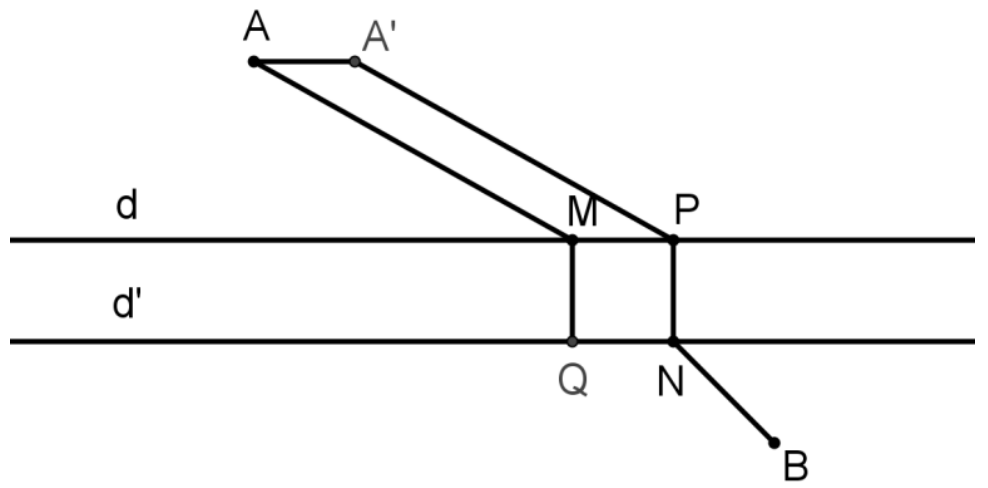

Figure 17: Mathematical solution

How does this problem have a relationship with example 2? Can we convert this problem to example 2? The answer is yes.

Consider translating $T_{\overline{M P}}: A \mapsto A^{\prime}$.

So $A M=A^{\prime} P$. Or $A M+N B=A^{\prime} P+N B$. The problem turns into example 2. (Nguyen, 2019)

\section{Pedagogical results and experiments}

This section refers to the experimental purpose, tasks and assessment of pedagogical experiment results.

\subsection{Experimental purpose and tasks}

- To test the scientific hypothesis that the article proposes through the practice of teaching geometric geometry in high school classes in the direction of integration.

- Check students' learning results through the implementation of geometric extreme teaching in the direction of integration.

\subsection{Assessment of pedagogical experiment results}

This section refers to the quantitative and qualitative analysis.

\subsubsection{Quantitative analysis}

In order to conduct a quantitative and qualitative analysis of the study of geometric extremes of students, in order to accurately assess pedagogical experiment results, we conduct a review in 2 steps:

- Processing results by mathematical statistical methods.

- Conduct statistical hypothesis test. 


\subsubsection{Processing results by mathematical statistical methods}

In order to perform a quantitative and qualitative analysis of extreme geometry learning in experimental class we have students do the end-of-course $t$ tests according to the program. The quantitative and qualitative analysis of student learning is based on the test score. Using the statistical test method, we have the following tables:

Table 1: Empirical distribution of frequency

\begin{tabular}{|c|c|c|c|c|c|c|c|c|c|c|c|c|}
\hline \multirow{2}{*}{$\begin{array}{l}\text { High } \\
\text { Schools } \\
\text { (Ho Chi } \\
\text { Minh City) }\end{array}$} & \multirow[b]{2}{*}{ Class } & \multicolumn{10}{|c|}{ Score $X_{i}$} & \multirow[b]{2}{*}{$\bar{X}$} \\
\hline & & 1 & 2 & 3 & 4 & 5 & 6 & 7 & 8 & 9 & 10 & \\
\hline \multirow{2}{*}{$\begin{array}{l}\text { Le Quy } \\
\text { Don } \\
(2018- \\
2019)\end{array}$} & $\begin{array}{c}11 \mathrm{~A} 1 \\
\mathrm{n}_{1}=40\end{array}$ & 0 & 0 & 0 & 2 & 8 & 6 & 11 & 9 & 3 & 1 & 6,75 \\
\hline & $\begin{array}{c}11 \mathrm{~A} 2 \\
\mathrm{n}_{2}=42\end{array}$ & 0 & 0 & 1 & 5 & 12 & 10 & 11 & 2 & 1 & 0 & 5,83 \\
\hline \multirow{2}{*}{$\begin{array}{l}\text { Nguyen } \\
\text { Thi Minh } \\
\text { Khai } \\
(2018 \text { - } \\
2019)\end{array}$} & $\begin{array}{c}11 \mathrm{~A} 4 \\
\mathrm{n}_{1}=40\end{array}$ & 0 & 0 & 0 & 1 & 7 & 7 & 12 & 9 & 2 & 2 & 6,87 \\
\hline & $\begin{array}{c}11 \mathrm{~A} 5 \\
\mathrm{n}_{2}=41\end{array}$ & 0 & 0 & 0 & 3 & 13 & 11 & 9 & 2 & 2 & 1 & 6,09 \\
\hline \multirow{2}{*}{$\begin{array}{l}\text { Marie } \\
\text { Curie } \\
(2018- \\
2019)\end{array}$} & $\begin{array}{l}11 \mathrm{D} 01 \\
\mathrm{n}_{1}=45\end{array}$ & 0 & 0 & 0 & 3 & 9 & 7 & 10 & 11 & 4 & 1 & 6,73 \\
\hline & $\begin{array}{l}11 \mathrm{D} 02 \\
\mathrm{n}_{2}=43\end{array}$ & 0 & 0 & 1 & 5 & 9 & 10 & 9 & 6 & 3 & 0 & 6,18 \\
\hline
\end{tabular}

Table 2: Empirical distribution of frequency $\left(f_{i} \%\right)$ of test results

\begin{tabular}{|c|c|c|c|c|c|c|c|c|c|c|c|c|}
\hline \multirow{2}{*}{$\begin{array}{c}\text { High } \\
\text { Schools } \\
\text { (Ho Chi } \\
\text { Minh City) }\end{array}$} & \multirow[b]{2}{*}{ Class } & \multicolumn{10}{|c|}{ Score $X_{i}$} & \multirow[b]{2}{*}{ Total } \\
\hline & & 1 & 2 & 3 & 4 & 5 & 6 & 7 & 8 & 9 & 10 & \\
\hline \multirow{2}{*}{$\begin{array}{l}\text { Le Quy } \\
\text { Don } \\
(2018 \text { - } \\
2019) \\
\end{array}$} & $\begin{array}{c}11 \mathrm{~A} 1 \\
\mathrm{n}_{1}=40\end{array}$ & 0 & 0 & 0 & 5 & 20 & 15 & 27,5 & 22,5 & 7,5 & 2,5 & $100 \%$ \\
\hline & $\begin{array}{c}11 \mathrm{~A} 2 \\
\mathrm{n}_{2}=42\end{array}$ & 0 & 0 & $\begin{array}{l}2, \\
4\end{array}$ & 11,9 & 28,6 & 23,8 & 26,2 & 4,8 & 2,4 & 0,0 & $100 \%$ \\
\hline \multirow{2}{*}{$\begin{array}{l}\text { Nguyen } \\
\text { Thi Minh } \\
\text { Khai } \\
(2018 \text { - } \\
\text { 2019) }\end{array}$} & $\begin{array}{c}11 \mathrm{~A} 4 \\
\mathrm{n}_{1}=40\end{array}$ & 0 & 0 & 0 & 2,5 & 17,5 & 17,5 & 30,0 & 22,5 & 5,0 & 5,0 & $100 \%$ \\
\hline & $\begin{array}{c}11 \mathrm{~A} 5 \\
\mathrm{n}_{2}=41\end{array}$ & 0 & 0 & 0 & 7,3 & 31,7 & 26,8 & 21,9 & 4,9 & 4,9 & 2,4 & $100 \%$ \\
\hline \multirow{2}{*}{$\begin{array}{l}\text { Marie } \\
\text { Curie } \\
(2018- \\
2019)\end{array}$} & $\begin{array}{l}11 \mathrm{D} 01 \\
\mathrm{n}_{1}=45\end{array}$ & 0 & 0 & 0 & 6,7 & 20,0 & 15,5 & 22,2 & 24,4 & 8,9 & 2,2 & $100 \%$ \\
\hline & $\begin{array}{l}11 \mathrm{D} 02 \\
\mathrm{n}_{2}=43\end{array}$ & 0 & 0 & $\begin{array}{l}2, \\
3\end{array}$ & 11,6 & 21,0 & 23,1 & 21,0 & 14,0 & 7,0 & 0,0 & $100 \%$ \\
\hline
\end{tabular}


Table 3: Accumulation frequency (the percentage of students gets $X_{i}$ or less)

\begin{tabular}{|c|c|c|c|c|c|c|c|c|c|c|c|}
\hline \multirow{2}{*}{$\begin{array}{c}\text { High } \\
\text { Schools (Ho } \\
\text { Chi Minh } \\
\text { City) }\end{array}$} & \multirow[b]{2}{*}{ Class } & \multicolumn{10}{|c|}{ Score $X_{i}$} \\
\hline & & 1 & 2 & 3 & 4 & 5 & 6 & 7 & 8 & 9 & 10 \\
\hline \multirow{2}{*}{$\begin{array}{l}\text { Le Quy Don } \\
\text { (2018 - 2019) }\end{array}$} & $\begin{array}{c}11 \mathrm{~A} 1 \\
\mathrm{n}_{1}=40\end{array}$ & 0 & 0 & 0 & 5,0 & 25,0 & 40,0 & 67,5 & 90,0 & 97,5 & 100,0 \\
\hline & $\begin{array}{c}11 \mathrm{~A} 2 \\
\mathrm{n}_{2}=42\end{array}$ & 0 & 0 & 2,4 & 14,3 & 42,9 & 66,7 & 92,9 & 97,6 & 100,0 & 100,0 \\
\hline \multirow{2}{*}{$\begin{array}{l}\text { Nguyen Thi } \\
\text { Minh Khai } \\
(2018-2019)\end{array}$} & $\begin{array}{c}11 \mathrm{~A} 4 \\
\mathrm{n}_{1}=40\end{array}$ & 0 & 0 & 0 & 2,5 & 20,0 & 37,5 & 67,5 & 90,0 & 95,0 & 100,0 \\
\hline & $\begin{array}{c}11 \mathrm{~A} 5 \\
\mathrm{n}_{2}=41\end{array}$ & 0 & 0 & 0 & 7,3 & 39,0 & 65,8 & 87,7 & 92,6 & 97,6 & 100,0 \\
\hline \multirow{2}{*}{$\begin{array}{l}\text { Marie Curie } \\
(2018-2019)\end{array}$} & $\begin{array}{l}11 \mathrm{D} 01 \\
\mathrm{n}_{1}=45\end{array}$ & 0 & 0 & 0 & 6,7 & 26,7 & 42,2 & 64,4 & 88,8 & 97,8 & 100,0 \\
\hline & $\begin{array}{l}11 \mathrm{D} 02 \\
\mathrm{n}_{2}=43\end{array}$ & 0 & 0 & 2,3 & 13,9 & 34,9 & 58,0 & 79,0 & 93,0 & 100,0 & 100,0 \\
\hline
\end{tabular}

Based on the results of processing by the mathematical statistics method above, we see that:

- The average score of the tests in the experimental class is higher than the control class (6.75 in the experimental class 11A1 compared with 5.83 in the control class 11A2; 6.87 in the 11A4 class compared to 6.09 in the control class $11 \mathrm{~A} 5 ; 6.73$ in experimental class 11D01 compared with 6.32 in 11D02 class).

Phase 1:

- Experimental class $11 \mathrm{~A} 1$ has $60.0 \%$ of students with a score of 7 or higher, $95.0 \%$ of students score 5 or higher.

- The control class 11A2 has $33.4 \%$ of students with a score of 7 or higher, $85.8 \%$ of students score 5 or higher.

Phase 2:

- Experimental class 11A4 (Nguyen Thi Minh Khai high school) has $62.5 \%$ of students achieving a score of 7 or higher and $97.5 \%$ of students scoring 5 or higher.

- The control class 11A5 (Nguyen Thi Minh Khai High School) has 34.1\% of the students with a score of 7 or higher and $92.7 \%$ of the students scoring 5 or higher.

- Experimental class 11D01 (Marie Curie High School) has 57.7\% of students scoring 7 or higher and $93.3 \%$ of students scoring 5 or higher.

- A control class of 11D02 (Marie Curie High School) has $44.3 \%$ of students achieving a score of 7 or higher and $88.4 \%$ of students achieving a score of 5 or higher.

\subsubsection{Test of statistical hypothesis}

We state the hypothesis $H_{0}$ : "The test results of the experimental class are not higher than the test results in the control class" and antithesis $\mathrm{H}_{\mathrm{t}}$ : "The test 
results of the experimental class are higher than the test results of the control class". To test the hypothesis $\mathrm{H}_{0}$, we use the following random quantity:

$$
Z=\frac{\bar{X}_{E}-\bar{X}_{C}}{\sqrt{\frac{S^{\prime 2} X_{E}}{n_{1}}+\frac{S^{\prime 2} X_{C}}{n_{2}}}}(Z \text { is called inspection quantity). }
$$

Inside:

- $\bar{X}_{E}$ : The average score of the experimental class.

- $\bar{X}_{C}$ : The average score of the control class.

- $\mathrm{n}_{1}$ : Number of students in the experimental class.

$-\mathrm{n}_{2}$ : Number of students in the control class.

- $S_{X_{E}}^{\prime 2}=\frac{1}{n_{1}} \sum n_{i}\left(x_{i}-\bar{X}_{E}\right)^{2}:$ Corrected sample variance of experimental class.

$-S_{X_{C}}^{\prime 2}=\frac{1}{n_{2}} \sum n_{i}\left(x_{i}-\bar{X}_{C}\right)^{2}:$ Corrected sample variance of control class.

- $n_{i}$ : Frequency of occurrence of score $x_{i}$.

Since $n_{1}, n_{2}>30$ is large enough, $Z$ has a probability distribution rule close to the standard probability distribution rule.

Call $Z_{t}$ as the critical value of the rejection domain (right side), $Z_{t}$ must satisfy the system: $\phi\left(Z_{t}\right)=\frac{1-2 \alpha}{2}$

( $\phi(x)$ is Laplace function; $\alpha$ is the chosen significance level).

If $Z>Z_{t}$, at the significance level of $\alpha, H_{0}$ is rejected, so the difference between $\bar{X}_{E}$ and $\bar{X}_{C}\left(\bar{X}_{E}>\bar{X}_{C}\right)$ is real.

Table 3.4 shows the test result of hypothesis $\mathrm{H}_{0}$ for the experimental phases: Choose $\alpha=0,05 \Rightarrow \phi\left(Z_{t}\right)=0,45$, then: $Z_{t}=1,65$ (Look up the value of the Laplace function).

Table 4: Test of hypothesis $\mathrm{H}_{0}$ of experimental phases 1 and 2

\begin{tabular}{|c|c|c|c|}
\hline Experimental phases & Phase 1 & \multicolumn{2}{|c|}{ Phase 2 } \\
\hline Statistics & & 40 & 45 \\
\hline $\mathrm{n}_{1}$ & 42 & 41 & 43 \\
\hline $\mathrm{n}_{2}$ & 6,75 & 6,87 & 6,73 \\
\hline $\bar{X}_{E}$ & 5,83 & 6.09 & 6.32 \\
\hline $\bar{X}_{C}$ & &
\end{tabular}




\begin{tabular}{|c|c|c|c|}
\hline$S_{X_{E}}^{\prime 2}=\frac{1}{n_{1}} \sum n_{i}\left(x_{i}-\bar{X}_{E}\right)^{2}$ & 2,09 & 1,96 & 2,28 \\
\hline$S_{X_{C}}^{\prime 2}=\frac{1}{n_{2}} \sum n_{i}\left(x_{i}-\bar{X}_{C}\right)^{2}$ & 1,65 & 1,84 & 2,26 \\
\hline Significance level & 0,05 & 0,05 & 0,05 \\
\hline$Z=\frac{\bar{X}_{E}-\bar{X}_{C}}{\sqrt{\frac{S^{\prime 2}{ }_{X_{E}}}{n_{1}}+\frac{S^{\prime 2}{ }_{X_{C}}}{n_{2}}}}$ & 3,07 & 2,60 & 1,72 \\
\hline$Z_{t}$ & 1,65 & 1,65 & 1,65 \\
\hline Comparison & $Z>Z_{t}$ & $Z>Z_{t}$ & $Z>Z_{t}$ \\
\hline $\begin{array}{c}\text { Conclusion of each phase of pedagogical } \\
\text { experiment. }\end{array}$ & $\begin{array}{l}\text { Reject } \mathrm{H}_{0} \\
\text { Accept } \mathrm{H}_{\mathrm{t}}\end{array}$ & $\begin{array}{c}\text { Reject } \\
\mathrm{H}_{0} \\
\text { Accept } \mathrm{H}_{\mathrm{t}}\end{array}$ & $\begin{array}{c}\text { Reject } \\
\mathrm{H}_{0} \\
\text { Accept } \\
\mathrm{H}_{\mathrm{t}}\end{array}$ \\
\hline
\end{tabular}

Thus, hypothesis $\mathrm{H}_{0}$ is rejected and antithesis $\mathrm{H}_{t}$ is accepted, it can be concluded: the difference in learning results between experimental class and control class is statistically significant, that is, teaching in the direction of integrated teaching is more effective than traditional teaching methods.

\subsubsection{Qualitative analysis}

For teachers:

Before conducting the experiment, we collaborated with the subject group to examine and survey to select the experimental class and the control class so that there was a similarity in quality and class size. After selecting the experimental class and the control class, we talked to the teachers of the experimental class and the control class about the orientations for innovating teaching methods in the current high schools and active teaching methods. Experimental teachers are provided with knowledge of modern teaching trends; the results of the scientists' research on integrated teaching and the viewpoint of the article on integrated teaching, including the expression of integrated activities of high school students in the study of extreme geometry. Through the sample lesson plan (for example, the example illustrated above) that the author of the paper designed, the experimental teacher imbued with the views on the lesson plans.

Experimental teachers have shown a good role of designing, organizing and controlling, helping students to be active and self-conscious in the view of integrated teaching, assessed by colleagues as practical and innovative teaching methods.

For students:

Through the experimental teaching process and analysis of two tests, it can be seen that students directly create knowledge through integration activities, 
explore new knowledge under the design, organization and control of teachers. Addition, students design and organize teaching activities from the integrated viewpoint has contributed to making the system of knowledge and skills formed systematically and more firmly. Next, students' ability to integrate is formed in a sustainable way. Finally, students are excited, proactive, positive and selflearning, demonstrating the central role of students in the teaching process allowing to confirm the effectiveness of integrated teaching methods.

\section{Conclusion}

The integrated teaching of geometric extremes in high school classes has initially helped teachers demonstrate the role of design, organization, control and students are active in the teaching process, in which students are the subject of discovery and knowledge creation, learning in activities and by working in collaboration and interaction with teachers and team members. The teaching in the spirit of integrated teaching has a positive effect on students' learning activities in a real way, contributing to fostering students' abilities. In integrated teaching, students not only formulate ways to create knowledge, self-study methods, but also formulate a discovery approach to discover and solve problems. Students mobilize different knowledge to solve practical problems. Integrating in extreme math problems helps students develop creative thinking, thinking about modeling real-world problems,... From the results of the experiment, the first step is to confirm the completed experimental purpose and the scientific hypothesis that the article proposes is acceptable.

\section{References}

Bailey, L. B (2010). The Impact of Sustained, Standards - Based Professional Learning on Secon and Third Grade Teachers' Content and Pedagogical Knowledge in Integrated Mathematics. Early childhood Education Journal, 38, 123 - 132.

Boyer (1990). Scholarship Reconsidered: Priorities of the Professoriate. San Francisco: JosseyBass.

Bui, H., Vu, V. T., Nguyen, V. G., \& Nguyen, H. Q. (2013). Education Dictionary. Vietnam: Encyclopaedic Dictionary Publishing House.

Ding, G, (2010). New Theoretical Approach Integrated Education and Technology. Frontiers' of Education in China, 5(1), 26-36. https://doi.org/10.1007/s11516-0100004-3

Do, H. T. (2016). Integrated teaching and developing students' ability (volume 1: Natural Science). University of Pedagogy Publishing House.

Vars, G. F., \& Beane, J. A. (2000). Integrative curriculum in a standards-based world. Washington, D.C: ERIC Digest, ERIC Document Reproduction Service No. ED 441618.

Ha, T. L. H., \& Dang, T. O. (2015). Some principles and methods of designing topics of integrated teaching. Science Journal, Hanoi University of Education, 6(2015), 204210.

Hoang, P., Bui, K. V., Chu, B. T., Dao, T., Hoang, T., Hoang, V. H., Le, K. C., Nguyen, M. C., Nguyen, N. T., Nguyen, T. N., Nguyen, T. K., Nguyen, V. K., Pham, H. V., Tran, C. V., Tran, N. P., Vu, N. B., \& Vuong, L. (1988). Vietnamese Dictionary. Social Science Publishing House. 
Hockett, J. A. (2009). Curriculum for highly able learners that conforms to general education and gifted education quality indicators. Journal for the Education of the Gifted, 32(3), 394-440. https://doi.org/10.4219/jeg-2009-857

Hornby, A. S. (2005). Oxford Advanced Learner's dictionary of Current English, UK, Oxford: Oxford University Press.

Irwin, C, (1992). Prospects-Quarterly Review of Education, 22(1). Unesco Publishing.

Lang, M., \& Olson, J. (2000). Integrated Science Teaching as a Challenge for Teachers to Develop New Conceptual Structures. Research in Science Education, 30(2), 213224. https://doi.org/10.1007/bf02461629

Marshall, J. (2005). Connecting Art, Learning, and Creativity: A case for Curriculum Integration. National Art Education Association, 46(3), 227-241. https://doi.org/10.1080/00393541.2005.11650076

Mei, L. (2009). Bridging disciplinary boundaries. Education Canada, 49(3), 40-43.

Nguyen, H. C (2006). Basic issues about the program and teaching process, Education Publishing House.

Nguyen, H. D (2001). The methods of solving geometric extreme problem, Science and Technology Publishing House.

Nguyen, K. H., \& Huynh, C. M. H. (2013). Integrated teaching in Australian high schools. Science Journal, Ho Chi Minh City University of Education, 42, 7-17.

Nguyen, N. G. (2017). Practical mathematical Methods and exams to grade 10 $10^{\text {th }}$. Ho Chi Minh Pedagogy University Publishing House.

Nguyen, N. G. (2019). Integrating Mathematics, Informatics and Physics, Hanoi National University Publishing House.

Nguyen, T. S. (2017). Developing integrated topics in teaching mathematics at high schools. (Doctoral thesis), Vietnam Institute of Educational Sciences.

Nguyen, T. T. B. \& Truong, T. P. (2019). The necessity of integrated methods in historical teaching in current high schools. Vietnam Education Magazine, 447, 29-32.

Park, M. (2008). Implementing Curriculum Integration: The Experiences of Korean Elementary Teachers. Asia Pacific Education Review, 9(3), 308-319. https://doi.org/10.1007/bf03026719

Tran, V. (2014). Solving practical problems in teaching Mathematics, Hue University Publishing House.

Wraga, W. G. (2009). Toward a connected core curriculum, Educational Horizons, 87(2), 88-96.

Zhbanova, K. S., Rule, Montgomery, S. E., \& Nielsen, L. E. (2010). Defining the Difference: Comparing Integrated and Traditional Single-Subject Lessons, Early Childhood Education Journal, 38, 251-258. https://doi.org/10.1007/s10643-0100405-1 